\title{
Testing an "In-Out" Targeting Procedure for Making Subtle Genomic Modifications in Mouse Embryonic Stem Cells
}

\author{
VICKY VALANCIUS AND OLIVER SMITHIES* \\ Department of Pathology, The School of Medicine, University of North Carolina, \\ Chapel Hill, North Carolina 27599-7525
}

Received 10 September 1990/Accepted 18 December 1990

\begin{abstract}
We have introduced a 4-bp insertion into the hypoxanthine phosphoribosyltransferase $(H P R T)$ gene of a mouse embryonic stem (ES) cell line by using an "in-out" targeting procedure. During the in step, a homologous integration reaction, we targeted a correcting plasmid to a partially deleted hprt $^{-}$locus by using an integrating vector that carried a 4-bp insertion in the region of DNA homologous to the target locus. HPRT recombinants were isolated by direct selection in hypoxanthine-aminopterin-thymidine (HAT) medium. The HAT $^{r}$ cell lines were then grown in medium containing 6-thioguanine (6-TG) to select for hprt $^{-}$revertants $^{-}$ resulting from the excision of the integrated vector sequences. The revertants were examined by Southern blot hybridization to determine the accuracy of this out reaction and the frequency of retaining the 4-bp modification in the genome. Of the 6-TGr colonies examined, $88 \%$ had accurately excised the integrated vector sequences; 19 of 20 accurate revertants retained the 4-bp insertion in the resulting hprt $^{-}$gene. We suggest a scheme for making the in-out targeting procedure generally useful to modify the mammalian genome.
\end{abstract}

Gene targeting, the method of using homologous recombination to modify the mammalian genome, can be used to introduce specific changes into cultured cells. By targeting the gene of interest in embryonic stem (ES) cells, these changes can be introduced into the germ lines of laboratory animals to study the effects of the modifications on whole organisms. During the gene targeting procedure, cloned DNA that is homologous to the target locus but has been modified in vitro to carry the intended change is introduced into tissue culture cells. The treated cells are then screened for accurate targeting to find those that have been properly modified.

Several schemes have been devised to aid in the isolation of the recombinants. A positively selectable helper gene is often included in the targeting vector to permit selection for cells that have taken up and expressed the introduced DNA. Typically, this selection results in a 1,000-fold enrichment for targeted cell lines $(7,10,11,20,24)$. Addition of a second, negatively selectable helper gene allows for selection against random insertion events (15). The positivenegative selection scheme achieves an additional 10- to 1,000 -fold enrichment for the homologous recombinants over the single positive selection procedure $(4,15)$. In both the single positive and the dual positive-negative selection systems, the positive selection element is introduced into the target locus in such a way as to interrupt or knock out the targeted region.

To create subtle modifications of the mammalian genome for fine-structure analyses or to mimic human genetic diseases resulting from small specific mutations, it is desirable to develop a targeting procedure that allows for easy identification of the recombinant cell lines (such as with the aid of selectable sequences) yet does not leave extraneous sequences in either the target or any other region of the genome in the final product. Recently, Steeg et al. (21) reported the introduction of a single base pair change into a mammalian genome without accompanying alterations.

\footnotetext{
* Corresponding author.
}

They targeted the RNA polymerase II gene in a mouse ES cell line in such a way that homologous recombinants, different from the parental line by only one or two base pairs, were directly selectable with $\alpha$-amanitin. Zimmer and Gruss (27) described the insertion of 20 base pairs into the Hox 1.1 locus in mouse ES cells without using any selection. The DNA was introduced by nuclear microinjection, and the polymerase chain reaction was used to detect recombinants. To date, there have been no other reports of successful gene targeting using this procedure.

Another procedure for making subtle changes in loci which are not directly selectable was described for the yeast system by Scherer and Davis (17). They targeted the HIS3 locus with an insertional plasmid carrying a mutated his 3 gene as well as the directly selectable $U R A 3$ gene. Targeted recombinants, isolated by the $\mathrm{URA}^{+}$phenotype, were expanded without selection then screened for the ura3 ${ }^{-}$ phenotype. They were able to isolate colonies that had lost all target vector sequences but now had only the mutated his 3 gene initially introduced into the genome by the targeted insertion event. As other yeast targeting techniques have been successfully transferred to the mammalian system, it should be possible to use this type of two-step selection scheme to make subtle changes in nonselectable loci in mammalian cells.

We have therefore tested the feasibility of using a two-step selection procedure in mouse ES cells to introduce a small change into a target locus. To this end, we targeted the mutant hypoxanthine phosphoribosyltransferase $\left(\right.$ hprt $\left.^{-}\right)$ gene in the cell line E-14TG2a (8) with an insertional plasmid capable of correcting the deletion mutation at this locus. The plasmid carried a 4-bp insertion in the region of DNA homologous to the target locus. $H P R T^{+}$targeted cell lines were isolated by direct selection with hypoxanthine-aminopterin-thymidine (HAT) medium, expanded, and then selected with 6-thioguanine (6-TG) to recover hprt $^{-}$revertants. The revertant colonies were examined by genomic Southern blot hybridization to confirm that the integrated vector DNA had been excised from the genome and to determine the frequency at which the intended 4-bp modifi- 
cation was obtained. Our results show that a subtle modification of the mouse HPRT gene can be achieved by using the two-step selection procedure. This "in-out" targeting procedure can be adapted to modify nonselectable loci with the aid of the HPRT minigene constructed by Reid et al. (16).

\section{MATERIALS AND METHODS}

Cell culture. The mouse ES cell line E-14TG2a was isolated as described previously $(8,25)$. Cells were grown in Dulbecco's modified Eagle's medium (GIBCO) supplemented with $15 \%$ heat-inactivated fetal calf serum (Flow) and $10 \mu \mathrm{M} 2$-mercaptoethanol (Sigma). The pluripotential nature of the ES cells was retained by supplementing each liter of growth medium with $10^{6} \mathrm{U}$ of recombinant human leukemia inhibitory factor, graciously supplied by N. Gough (Walter and Eliza Hall Institute, Melbourne, Victoria, Australia). Because feeder layers were not used, all culture dishes were coated with $0.1 \%$ sterile gelatin to ensure cell adhesion. HAT medium was standard culture medium supplemented with $120 \mu \mathrm{M}$ hypoxanthine, $0.4 \mu \mathrm{M}$ aminopterin, and $20 \mu \mathrm{M}$ thymidine. 6-TG selection was carried out in standard medium containing $10 \mu \mathrm{M}$ 6-TG. Cultures were incubated at $37^{\circ} \mathrm{C}$ in an atmosphere of $5 \% \mathrm{CO}_{2}$. They were checked periodically for mycoplasma contamination.

Vectors. Plasmid pNMR133 has already been described (6). It contains $5 \mathrm{~kb}$ of DNA identical to the exon 3 target region of the mouse $H P R T$ gene, except for a 4-bp insertion that destroys a unique HindIII site and consequently generates a new NheI site in intron 2 . It also carries the human HPRT promoter and exon 1 sequences (which have been shown to function in mouse cells) and the mouse exon 2 region.

Plasmid pNMR133D200 was derived from pNMR133 by removing a 200-bp BglII fragment from intron 2 .

DNA preparation. Targeting vector DNAs were prepared by standard methods, omitting the $\mathrm{CsCl}$ purification, which we found unnecessary (unpublished results). All targeting DNAs were linearized by restriction enzyme digestion, using the manufacturers' recommended conditions, prior to electroporations. Digested DNAs were ethanol precipitated and resuspended in sterile TE buffer $(0.05 \mathrm{M}$ Tris, $0.001 \mathrm{M}$ EDTA).

DNA transfers and selections. The vectors were introduced into the ES cells by electroporation (2). The cells were grown in $100-\mathrm{mm}$ culture dishes (as described above) to a density of $1 \times 10^{7}$ to $2 \times 10^{7}$ cells per dish in nonselective medium. Cultures were trypsinized, centrifuged, and then resuspended in nonselective medium to a density of $4 \times 10^{7}$ to $10 \times 10^{7}$ cells per $\mathrm{ml}$. A $0.5-\mathrm{ml}$ sample of the cell suspension was added to each microfuge tube, and prepared DNA was then added to a final concentration of $5 \mathrm{nM}$. The cell-DNA mixtures were incubated on ice for $20 \mathrm{~min}$, loaded into an electroporation chamber precooled on ice (length, 5 $\mathrm{mm}$; cross section, $100 \mathrm{~mm}^{2}$ ), and exposed to a $1-\mathrm{s}$ electrical pulse from a $250-\mu \mathrm{F}$ capacitor charged to $300 \mathrm{~V}$. Cells were immediately removed from the chamber and plated into five $100-\mathrm{mm}$ culture dishes. The plates had been prepared by gelatinization and contained $7 \mathrm{ml}$ of nonselective medium. The cells were allowed to recover overnight. The next day, the number of colonies in each dish was determined by counting, and HAT selection was then applied.

Cultures to be assayed for the loss of HPRT function by selection in 6-TG were maintained under HAT selection for at least 1 month prior to the start of the assay in order to kill any accumulated $\mathrm{hprt}^{-}$cells. These cultures were tryp- sinized, counted, and then replated at a density of $0.5 \times 10^{7}$ to $1 \times 10^{7}$ cells per plate in nonselective medium. They were grown without selection for 3 or 4 days to allow spontaneous revertants time to purge residual $H P R T$ transcripts or protein. Selection was then started by applying 6-TG medium.

All selections were maintained for 16 days, with feeding as necessary. Targeting and reversion frequencies were determined by counting the number of resistant colonies obtained for each experiment. Individual colonies were picked by using cloning rings into 24 -well $(1 \mathrm{ml}$ per well) dishes and maintained under selection. Cultures were transferred to 60-mm culture dishes and then either harvested for genomic DNA preparation or transferred to $100-\mathrm{mm}$ dishes for further expansion.

Genomic DNA preparation and characterization. DNA was prepared from expanded clones by using conventional procedures. Restriction enzyme digestions were done according to manufacturers' specifications, incubating overnight. After electrophoresis on $\mathbf{0 . 8 \%}$ agarose gels, Southern blotting was done by standard techniques.

Probes. Two probes were used, a 250-bp RsaI fragment from intron 3 and a 300-bp HindIII-XhoI fragment from the human cDNA which includes exons 3 to 6 but is specific for the mouse exon 3 element (6). Both probes hybridize to sequences present in the endogenous locus as well as on the targeting vectors. For each blot, 25 to $50 \mathrm{ng}$ of purified fragment was radiolabeled with ${ }^{32} \mathrm{P}-\mathrm{dCTP}$ by the randomprimed oligonucleotide method, using a Boehringer Mannheim kit. Four-hour prehybridizations and overnight hybridizations were done in $50 \%$ formamide solutions at $42^{\circ} \mathrm{C}$. Blots were washed to a stringency of $1 \times \operatorname{SSC}(0.15 \mathrm{M} \mathrm{NaCl}$ plus $0.015 \mathrm{M}$ sodium citrate) at $68^{\circ} \mathrm{C}$. Washed blots were exposed to preflashed XAR-5 film at $-70^{\circ} \mathrm{C}$.

\section{RESULTS}

In step: the integration event. The first step in the two-step targeting procedure is a homologous integration event that incorporates vector DNA carrying the desired modification into the genome. We used the method of Doetschman et al. (6) to introduce into mouse ES cells an integrating targeting vector that carries a 4-bp insertion in the second intron of the HPRT gene. Either plasmid pNMR133 or plasmid pNMR133D200 (which has a 200-bp gap in the region homologous to the target locus) was electroporated into the male mouse-derived ES cell line E-14TG2a. This cell line, isolated by Hooper et al. (8) as a spontaneous mutation in culture, carries a nonreverting deletion of the promoter and first two exons of the nine-exon, 33-kbp, X-linked HPRT gene (25), rendering it phenotypically hprt $^{-}$. Both targeting vectors contain approximately $5 \mathrm{~kb}$ of DNA identical in sequence to the exon 3 target region of the hprt $^{-}$gene except for the intended modification: a 4-bp insertion in intron 2 that destroys a unique HindIII site. They also carry the human $H P R T$ promoter and exon 1 sequences and the mouse exon 2 region.

The homologous integration event generates a duplication of the 5-kb target region separated by the remainder of the vector sequences (Fig. 1). The duplicated regions are identical with the exception of the 4-bp insertion, identified by a missing HindIII site, that is located on the downstream repeat. This event restores the promoter and first two exons deleted from the locus, generating $\mathrm{HPRT}^{+}$targeted recombinants that can be directly selected with HAT-containing medium.

We isolated three independent $\mathrm{HPRT}^{+}$cell lines by selec- 
A
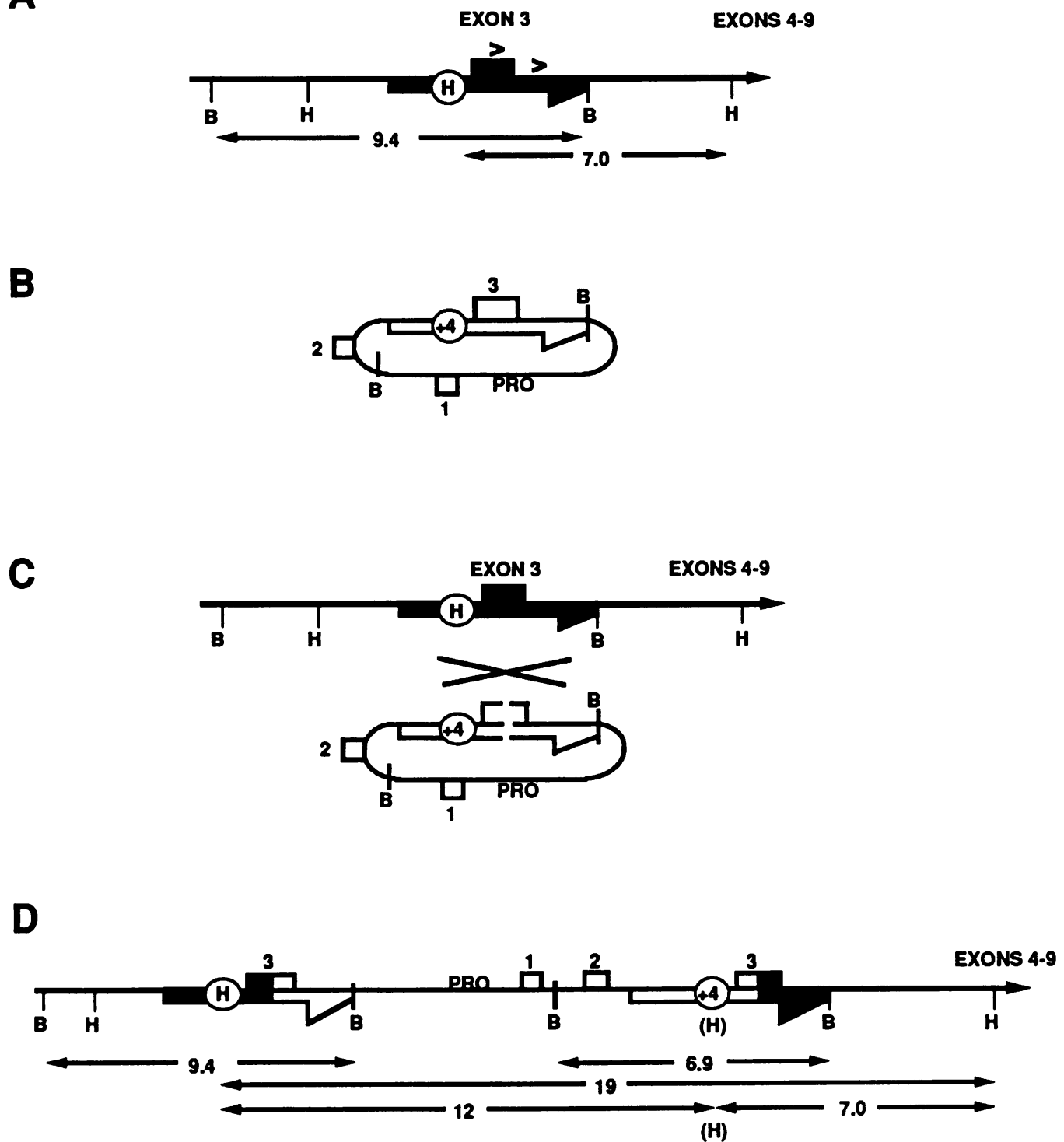

FIG. 1. The integration reaction. (A) The prt $^{-}$locus found in cell line E-14TG2a. The 5-kb target region is denoted by the thick black arrow. $>$, Regions used as probes. These sequences are also present in the targeting vectors. ( $)$, The HindIII site that has been destroyed in the targeting vectors. (B) The pNMR133 targeting vector $(12 \mathrm{~kb}) .+4$ denotes the $4 \mathrm{bp}$ insertion carried by this plasmid; it destroys the HindIII (@) site. Plasmid pNMR133D200 is identical to this plasmid except that a 200-bp BgllI fragment has been removed from the region of homology. The open arrow denotes the region of DNA homologous to the target locus. PRO, Promoter; 1, 2, and 3, exons. (C) The homologous integration reaction with pNMR133 linearized at the $X h o l$ site in the middle of the $H P R T$ sequences. (D) The resulting $H P R T^{+}$ recombinant locus. The 5-kb duplicated regions (the large half-black, half-open arrows) are composed of both target locus and vector-derived sequences. B, Bam HI; H, HindIII.

tion in HAT medium at an average frequency of $2.8 \times 10^{-6}$ per electroporated cell and then confirmed that these cell lines were targeted by genomic Southern blot hybridization. The blots were probed either with a 250-bp RsaI fragment from intron 3 or with a 300-bp HindIII-XhoI fragment from the human cDNA that specifically hybridizes to the mouse exon 3. Both probes hybridize to sequences found in the genome as well as on the targeting vectors (Fig. 1A). All of the cell lines examined contained the expected recombinant locus depicted in Fig. 1D, indicating that a single copy of the targeting vectors had integrated into the E-14TG2a hprt $^{-}$ gene.
Cell lines A and C hybridized to the single 19-kb HindIII fragment expected for a simple insertion of the $12-\mathrm{kb}$ vector into the 7-kb endogenous fragment. Cell line D hybridized to two HindIII fragments, the endogenous 7-kb and the vector $12-\mathrm{kb}$ fragments. This cell line, generated with plasmid pNMR133D200, has lost the 4-bp insertion as a consequence of the integration event (see reference 6), so that revertants obtained from this line could not be properly modified. However, it was used in the excision experiments (see below) since it could still generate useful information about the frequency and accuracy of the excision reaction. Bam HI digestion of all recombinants revealed the expected $9.4-\mathrm{kb}$ 
A

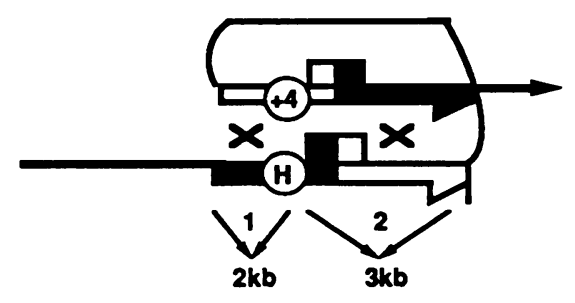

$\mathbf{B}$

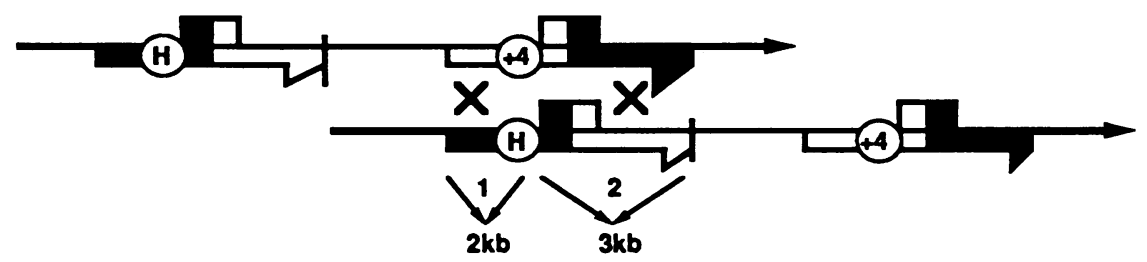

C

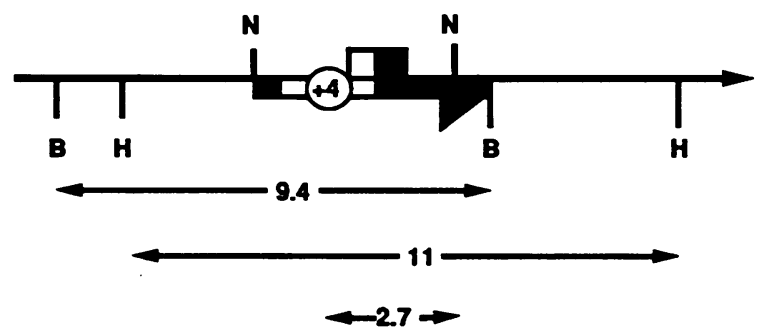

D

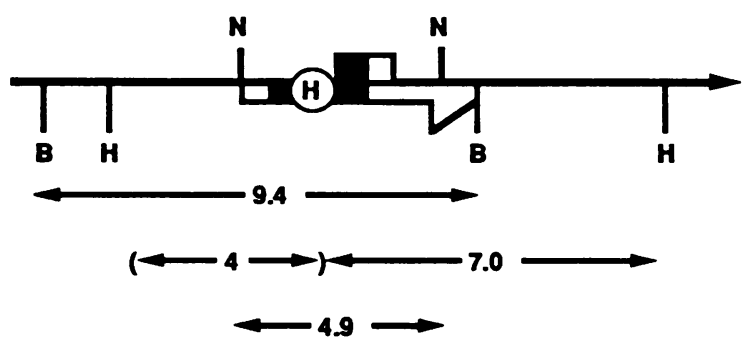

FIG. 2. The excision reaction. (A) Homologous excision via intrachromosomal recombination between the 5-kb duplications. Crossover in region $1(2 \mathrm{~kb})$ retains the 4-bp insertion in the excision product; crossover in region $2(3 \mathrm{~kb})$ removes the 4-bp insertion. (B) Homologous excision via unequal sister chromatid exchange. One of the resulting chromosomes (the excision product) contains a single copy of the duplicated region. Regions 1 and 2 are as in panel A. (C) The desired product: the hprt ${ }^{-}$locus now containing the 4-bp insertion. (D) The other possible hrt $^{-}$locus: the E-14TG2a starting locus (Fig. 1A). The 4-kb fragment in parentheses does not hybridize to our probes; it is included in this figure to clarify the origin of the 11-kb band in panel C. B, Bam HI; H, HindIII; N, NheI.

endogenous band and the 6.9-kb vector-derived band. No extraneous bands could be detected, confirming that all of the recombinants carried single-site, single-copy insertions of the vector DNAs (see Fig. 3). In addition to these three lines, one more cell line, $\mathrm{B}$, generated previously in the laboratory (6) was used in the excision studies (see below). This line carries the same recombinant locus found in lines A and $\mathrm{C}$.

Out step: the excision event. The second step in the two-step targeting procedure is a spontaneous event that excises from the genome the vector sequences that integrated in the first step. A homologous recombination event between the regions duplicated during the in reaction can occur by either intrachromatid recombination (Fig. 2A) or unequal sister chromatid exchange (Fig. 2B). A crossover event in the $2-\mathrm{kb}$ region 1 will leave the 4-bp insertion in the genome; crossing over in region 2 , which is $3 \mathrm{~kb}$, will excise the 4-bp modification along with the vector sequences (Fig. $2 \mathrm{~A})$ or move it to the $\left(H P R T^{+}\right)$triplicated chromosome (Fig. 2B). Either way, the excision event removes the vectorderived promoter and first two exons, causing a reversion to the prt $^{-}$phenotype. Such revertants can be selected with the nucleoside analog 6-TG.

The four $\mathrm{HAT}^{\mathrm{r}}$ cell lines described above were used to study the excision (out) reaction. They all carry essentially the same HPRT locus: a duplication of $5 \mathrm{~kb}$ separated by 7 $\mathrm{kb}$ of plasmid-derived unique sequence (Fig. 1D). ES cell line D-3 (5), which carries the wild-type $H P R T$ locus, was 
TABLE 1. Frequency of the out reaction

\begin{tabular}{|c|c|c|c|c|}
\hline Cell line & $\begin{array}{c}\text { Cells plated } \\
\left(10^{7}\right)\end{array}$ & $\begin{array}{l}\text { Colonies } 24 \mathrm{~h} \\
\text { post }\left(10^{6}\right)^{a}\end{array}$ & $\begin{array}{c}\text { 6-TGr } \\
\text { colonies }^{b}\end{array}$ & $\begin{array}{l}\text { Reversion } \\
\text { frequency }^{c}\end{array}$ \\
\hline A & 2.90 & 3.2 & 23 & $7.9 \times 10^{-7}$ \\
\hline B & 2.2 & 3.2 & 13 & $5.9 \times 10^{-7}$ \\
\hline $\mathrm{C}$ & 4.2 & 6.4 & 14 & $3.3 \times 10^{-7}$ \\
\hline D & 3.8 & 4.0 & 56 & $14.7 \times 10^{-7}$ \\
\hline Total & 13.1 & & 106 & $8.1 \times 10^{-7}$ \\
\hline D-3 (control) & 5.6 & 4.8 & 0 & $<1.8 \times 10^{-8}$ \\
\hline
\end{tabular}

${ }^{a}$ Number of colonies counted the day after replating, reflecting a 10 to $20 \%$ plating efficiency (see text).

${ }^{b}$ Number of colonies counted after 2 weeks of 6-TG selection.

${ }^{c}$ Number of $6-\mathrm{TG}^{r}$ colonies obtained per plated cell.

used as a control in these experiments to determine the spontaneous rate of mutation from $\mathrm{HPRT}^{+}$to $\mathrm{hprt}^{-}$at the normal locus. The experiments were performed as described in Materials and Methods. The day after replating, the number of colonies observable in each dish was determined by counting. Typically, ES cells form one colony for every 5 to 10 cells plated (Table 1 ). This is due to their propensity to form aggregates, not to a high death rate. That is to say, each colony found the day after replating is composed of 5 to 10 individual cells. Although this aggregation may interfere with our 6-TG selections as a result of metabolic crossfeeding (9), it cannot be avoided (see Discussion).

The number of 6-TG ${ }^{r}$ colonies obtained for each line examined and calculated reversion frequencies are listed in Table 1. As shown, all four HAT ${ }^{\mathrm{r}}$ lines initially generated by gene targeting reverted to the prt $^{-}$phenotype at similar frequencies, averaging $8 \times 10^{-7} 6-\mathrm{TG}^{\mathrm{r}}$ colonies isolated for every HAT $^{\mathrm{r}}$ cell plated. Control cell line D-3, which carries the wild-type $H P R T$ locus, failed to produce any $6-\mathrm{TG}^{\mathrm{r}}$ colonies from $5.6 \times 10^{7}$ cells plated. Thus, the spontaneous mutation frequency at the HPRT locus, for cells preselected with HAT, is less than $1.8 \times 10^{-8}$. This result is consistent with the rate of $1.5 \times 10^{-8}$ per cell generation reported for the locus by Caskey and Kruh (3).

Several of the individual 6-TG ${ }^{r}$ colonies were analyzed further by genomic Southern blot hybridization, using the $H P R T$-specific probes described above. The number of colonies examined from each line and a summary of the results obtained from the Southern blot hybridizations are presented in Table 2. Representative Southern blots are presented in Fig. 3.

Of a total of $266-\mathrm{TG}^{\mathrm{r}}$ colonies examined, $23(88 \%)$ had executed the out reaction and accurately excised the integrated vector sequences from the genome, as determined by the genomic Southern blots. They all revealed a single 9.4-kb Bam HI band upon hybridization, the size predicted

TABLE 2. Accuracy of the out reaction

\begin{tabular}{lccc}
\hline Cell line & $\begin{array}{c}\text { Colonies } \\
\text { examined }\end{array}$ & $\begin{array}{c}\text { Accurate } \\
\text { revertants }^{a}\end{array}$ & $\begin{array}{c}\text { Revertants with } \\
\text { 4-bp insert }\end{array}$ \\
\hline A & 3 & 2 & $2 / 2$ \\
B & 9 & 7 & $6 / 7$ \\
C & 11 & 11 & $11 / 11$ \\
D & 3 & 3 & NA \\
Total & 26 & 23 & $19 / 20$ \\
\hline
\end{tabular}

${ }^{a}$ Number of colonies containing the expected hprt $^{-}$locus.

${ }^{b}$ Number of $\mathrm{hprt}^{-}$colonies that retain the 4-bp insertion presented as a fraction of the number of accurate revertants obtained.

NA, Not applicable; this cell line does not carry the 4-bp insertion.
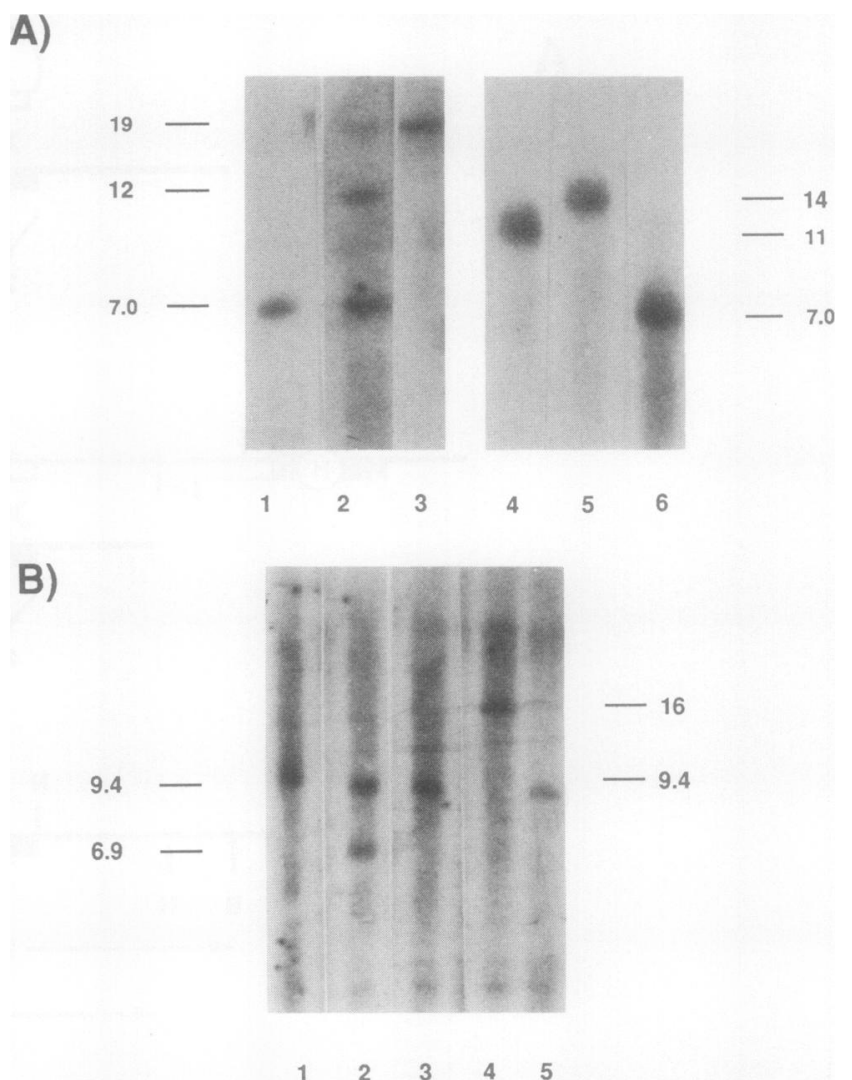

FIG. 3. Representative Southern blots. (A) HindIII-digested genomic DNAs hybridized to the exon 3 probe. Lanes: 1 , starting cell line E-14TG2a $\left(\mathrm{hprt}^{-}\right) ; 2, \mathrm{HAT}^{\mathrm{r}}$ cell line without the 4-bp insertion $\left(H P R T^{+}\right) ; 3, H_{A T} T^{r}$ cell line with the 4-bp insertion $\left(H P R T^{+}\right) ; 4$, correctly modified $\mathrm{hprt}^{-}$gene (with the 4-bp insertion); 5, unusual 6-TG ${ }^{\mathrm{r}}$ revertant (see text); 6 , accurate hprt $^{-}$revertant that has lost the 4-bp insertion. (B) BamHI-digested genomic DNAs hybridized to the 250 -bp intron 3 probe. Lanes 1 and 2 are as in panel $A$, and lanes 3 to 5 are as lanes 4 to 6 in panel $A$.

for a simple homologous excision event. This is the same BamHI fragment found in the parental E-14TG2a hprt locus. HindIII digestion of the revertant DNAs is expected to reveal one of two bands upon hybridization: either an $11-\mathrm{kb}$ fragment, if the crossover occurs in region 1 (Fig. 2A and B) and the 4-bp insertion introduced by the in event is retained, or a $7-\mathrm{kb}$ fragment, if the crossover occurs in region 2 and the modification is removed from the prt $^{-}$ genome.

Of the 23 out revertants examined, 20 were derived from $\mathrm{HPRT}^{+}$cell lines that carried the 4-bp insertion initially introduced by the targeted integration event; 19 of these colonies contain the single 11-kb HindIII fragment, indicative of the accurate excision event which retains the 4-bp insertion. Thus, these 19 colonies have been correctly modified by the in-out targeting procedure. Only 1 of these 20 revertant colonies lost the 4-bp modification, as determined by the presence of a 7-kb HindIII fragment. Therefore, $95 \%$ of the accurate revertants which could have retained the 4-bp insertion did so. The three remaining colonies which were found to have been generated by the out reaction were derived from the HAT $^{\mathrm{r}}$ cell line D. As this cell line does not carry the 4-bp modification, the revertants revealed only the 7-kb HindIII band upon hybridization. 
To confirm that the 11-kb HindIII band characterizing our accurately modified $\mathrm{hprt}^{-}$revertants retained the 4-bp insertion initially introduced by the targeting vector, we digested two of the genomic DNAs with NheI. The 4-bp insertion introduced to destroy the HindIII site in the original targeting vector generates a unique NheI site. In the case of the revertants that have retained the 4-bp insertion (11-kb HindIII), NheI digestion will generate a $2.7-\mathrm{kb}$ band which hybridizes to our probes. In the case of the revertants which have lost the insertion (7-kb HindIII), a 4.9-kb band will result (Fig. 2). The accurately modified revertant does contain a 2.7-kb NheI fragment which hybridizes to our probe, confirming the presence of the 4-bp insertion, and the revertant which has lost the 4-bp insertion reveals a 4.9-kb fragment upon hybridization (data not shown).

The other three colonies examined were found to contain aberrant $\mathrm{hprt}^{-}$loci that did not arise by the predicted homologous excision reaction. They contained a single 14-kb HindIII fragment and a 16-kb BamHI fragment that hybridized to our probes. These fragments failed to hybridize to a plasmid-specific probe (data not shown), indicating that the target vector sequences have been excised from the genome. Since the bands are not the expected sizes, these colonies were probably generated by an alternate excision reaction. Because they account for only $12 \%$ of the $6-\mathrm{TG}^{\mathrm{r}}$ colonies obtained, we did not examine them further.

\section{DISCUSSION}

We have succeeded in modifying the genome of a mouse ES cell line, introducing a 4-bp insertion, by using a two-step in-out targeting procedure. The average frequency of the in reaction was found to be $2.8 \times 10^{-6}$, in agreement with other reports for gene targeting in murine systems $(6,7,10,20,21$, $23,24)$. The frequency of the out reaction, $8 \times 10^{-7} \mathrm{per}$ HAT $^{r}$ cell plated, is approximately $30 \%$ that of the in reaction. This frequency is $\mathbf{4 0 - f o l d ~ h i g h e r ~ t h a n ~ t h e ~ s p o n t a - ~}$ neous mutation rate at the normal $H P R T$ locus. Of the 6-TG colonies isolated, $88 \%$ had accurately excised the target vector sequences from the genome.

The mechanism of the out reaction, the excision event which generates 6-TG ${ }^{\mathrm{r}}$ colonies, is likely to be either intrachromatid recombination between the 5-kb duplicated regions resulting from the insertion event (12-14) or an unequal sister chromatid recombination event between these same regions $(19,22)$. Both modes are depicted in Fig. 2. Our current information does not allow us to distinguish between them. However, it is of considerable interest that $95 \%$ of the 6-TG ${ }^{\mathrm{r}}$ colonies examined from the HAT $^{\mathrm{r}}$ lines carrying the 4-bp insertion retained this insertion in the final locus. Because the modification is located $2 \mathrm{~kb}$ from the $5^{\prime}$ end of the duplicated region and $3 \mathrm{~kb}$ from the $3^{\prime}$ end, one would expect a 3:2 ratio in favor of losing the insertion if a simple crossover, occurring randomly along the length of the repeat, were responsible for the excision event. As this ratio is not observed, the 2-kb region may contain a hot spot for recombination.

Thompson et al. (25) have also examined reversion of an $H P R T^{+}$targeted recombinant cell line that was generated in much the same way as ours. They similarly found that the target vector sequences had been excised from the genome in those cells which spontaneously reverted to the $\mathrm{hrt}^{-}$ phenotype. Intrachromosomal recombination events occurring between direct repeats generated by gene targeting at the immunoglobulin Mu heavy-chain locus have been examined by Baker (1). The downstream repeat contained a 2-bp deletion relative to the upstream region. The majority of the recombinants were found to be gene conversion products; the excision products that did arise contained the longer (upstream) and shorter (downstream) repeats with equal frequency. This observation probably indicates that the bias we observed toward retaining the 4-bp insertion is gene specific rather than genome wide.

It has been shown that metabolic cross-feeding can interfere with 6-TG selections (9); therefore, the reversion frequency that we determined may be an underestimate. Because the ES cells always form aggregates upon plating, we could not eliminate the possibility of such cross-feeding. When using the in-out targeting procedure in other cell lines, it may be useful to plate HAT $^{\mathrm{r}}$ cells at a lower density to minimize the potential of revertant loss due to such crossfeeding.

An important part of our protocol (as described in Materials and Methods) was that the ES cells were not grown on feeder layers. Instead, the pluripotential nature of the cells was retained by supplementing the growth medium with purified human leukemia inhibitory factor $(18,26)$. This modification greatly simplifies the two-step selection procedure. Otherwise, the ES cells would have to be grown successively on two different feeder layers possessing opposite $H P R T$ genotypes, requiring an adaptation stage between the selections. Also, 6-TG selection occurs slowly, requiring feeder-grown cultures to be passaged. We were able to simplify the selection procedure by eliminating this passage requirement. We were also able to isolate single clonal populations of the revertants, allowing for a more accurate determination of the reversion frequency.

The rationale for performing our experiments was to determine the feasibility of using an in-out targeting procedure to modify the mammalian genome. We have shown that both the integration and excision events occur accurately and at frequencies sufficient for use in a two-step targeting technique. Although we tested the two-step procedure in the directly selectable $H P R T$ locus, the same procedure should be adaptable to modify nonselectable loci in an $\mathrm{hprt}^{-}$cell line by using the HPRT minigene described by Reid et al. (16).

The minigene would be carried on an integrating targeting vector, thereby allowing selection to be used for both the integration and excision events. Homologous recombinants are likely to be found after the in step at a frequency of 1 in $1,000 \mathrm{HAT}^{\mathrm{r}}$ cells, this being the ratio of transformed to targeted cells reported previously $(20,24)$. The targeted cell lines can then be identified by the polymerase chain reaction (see reference 27, for example). Including a small gap in the region of homology on the insertional vector provides a convenient primer binding site, since all gaps are repaired during the homologous insertion event (25a). Excision-derived $h \mathrm{prt}^{-}$revertants are likely to be found after the out step at a frequency of nearly 1 in $10^{6}$ per targeted cell line.

The two-step selection scheme permits an enrichment for homologous recombinants carrying the desired modification, but the selectable sequences are not present in the final product. This in-out targeting procedure has the potential to be used in a variety of situations to create subtle modifications of the mammalian genome, a necessary prerequisite for fine-structure genetic analyses in mammalian systems.

\section{ACKNOWLEDGMENTS}

We thank Robert Schiestl for helpful discussions, Nick Gough for supplying leukemia inhibitory factor, Denise Dolenak and Hyung- 
Suk Kim for performing preliminary experiments, and Sylvia Hiller for help with the Southern blots. We also thank Robert Schiestl, Tom Petes, and members of our laboratory group for critical readings of the manuscript.

This work was supported by grants GM20069 and HL37001 from the National Institutes of Health.

\section{REFERENCES}

1. Baker, M. D. 1989. High-frequency homologous recombination between duplicate chromosomal immunoglobulin Mu heavychain constant regions. Mol. Cell. Biol. 9:5500-5507.

2. Boggs, S. S., R. G. Gregg, N. Borenstein, and O. Smithies. 1986. Efficient transformation and frequent single-site, single-copy insertion of DNA can be obtained in mouse erythroleukemia cells transformed by electroporation. Exp. Hematol. 14:988994.

3. Caskey, C. T., and G. D. Kruh. 1979. The HPRT locus. Cell 16:1-9.

4. DeChiara, T. M., A. Efstratiadis, and E. J. Robertson. 1990. A growth-deficiency phenotype in heterozygous mice carrying an insulin-like growth factor II gene disrupted by targeting. Nature (London) 345:78-80.

5. Doetschman, T. C., H. Eistetter, M. Katz, W. Schmidt, and R. Kemler. 1985. The in vitro development of blastocyst-derived embryonic stem cell lines: formation of visceral yolk sac, blood islands and myocardium. J. Embryol. Exp. Morphol. 87:27-45.

6. Doetschman, T., R. G. Gregg, N. Maeda, M. L. Hooper, D. W. Melton, S. Thompson, and O. Smithies. 1987. Targetted correction of a mutant HPRT gene in mouse embryonic stem cells. Nature (London) 330:576-578.

7. Doetschman, T., N. Maeda, and O. Smithies. 1988. Targeted mutation of the HPRT gene in mouse embryonic stem cells. Proc. Natl. Acad. Sci. USA 85:8583-8587.

8. Hooper, M., K. Hardy, A. Handyside, S. Hunter, and M. Monk. 1987. HPRT-deficient (Lesch-Nyhan) mouse embryos derived from germline colonization by cultured cells. Nature (London) 326:292-295.

9. Hooper, M. L., and J. H. Subak-Sharpe. 1981. Metabolic cooperation between cells. Int. Rev. Cytol. 69:45-104.

10. Jasin, M., and P. Berg. 1988. Homologous integration in mammalian cells without target gene selection. Genes Dev. 2:13531363.

11. Joyner, A. L., W. C. Skarnes, and J. Rossant. 1989. Production of a mutation in mouse En-2 gene by homologous recombination in embryonic stem cells. Nature (London) 338:153-156.

12. Liskay, R. M., A. Letsou, and J. L. Stachelek. 1987. Homology requirements for efficient gene conversion between duplicated chromosomal sequences in mammalian cells. Genetics 115:161167.

13. Liskay, R. M., and J. L. Stachelek. 1983. Evidence for intrachromosomal gene conversion in cultured mouse cells. Cell 35:157-165.
14. Liskay, R. M., J. L. Stachelek, and A. Letsou. 1984. Homologous recombination between repeated chromosomal sequences in mouse cells. Cold Spring Harbor Symp. Quant. Biol. 49:183189.

15. Mansour, S. L., K. R. Thomas, and M. R. Capecchi. 1988. Disruption of the proto-oncogene int-2 in mouse embryo-derived stem cells: a general strategy for targeting mutations to non-selectable genes. Nature (London) 336:348-352.

16. Reid, L. H., R. G. Gregg, O. Smithies, and B. H. Kohler. 1990. Regulatory elements in the introns of the HPRT gene are necessary for its expression in mouse embryonic stem cells. Proc. Natl. Acad. Sci. USA 87:4299-4303.

17. Scherer, S., and R. W. Davis. 1979. Replacement of chromosome segments with altered DNA sequences constructed in vitro. Proc. Natl. Acad. Sci. USA 76:4951-4955.

18. Smith, A. G., J. K. Heath, D. D. Donaldson, G. G. Wong, J. Moreau, M. Stahl, and D. Rogers. 1988. Inhibition of pluripotential embryonic stem cell differentiation by purified polypeptides. Nature (London) 336:688-690.

19. Smithies, O., G. E. Connell, and G. H. Dixon. 1962. Chromosomal rearrangements and the evolution of haptoglobin genes. Nature (London) 196:232-236.

20. Smithies, O., R. G. Gregg, S. S. Boggs, M. A. Koralewski, and R. S. Kucherlapati. 1985. Insertion of DNA sequences into the human chromosomal B-globin locus by homologous recombination. Nature (London) 317:230-234.

21. Steeg, C. M., J. Ellis, and A. Bernstein. 1990. Introduction of specific point, mutations into RNA polymerase II by gene targeting in mouse embryonic stem cells: evidence for a DNA mismatch repair mechanism. Proc. Natl. Acad. Sci. USA 87: $4680-4684$.

22. Sturtevant, A. H. 1925. The effects of unequal crossing over at the Bar locus in Drosophila. Genetics 10:117-147.

23. Thomas, K. R., and M. R. Capechi. 1987. Site-directed mutagenesis by gene-targeting in mouse embryo-derived stem cells. Cell 51:503-512.

24. Thomas, K. R., K. R. Folger, and M. R. Capecchi. 1986. High frequency targeting of genes to specific sites in the mammalian genome. Cell 44:419-428.

25. Thompson, S., A. R. Clark, A. M. Pow, M. L. Hooper, and D. W. Melton. 1989. Germline transmission and expression of a corrected HPRT gene produced by gene targeting in embryonic stem cells. Cell 56:313-321.

25a.Valancius, V., and $\mathrm{O}$. Smithies. Unpublished data.

26. Williams, R. L., D. J. Hilton, S. Pease, T. A. Willson, C. L. Stewart, D. P. Gearing, E. F. Wagner, D. Metcalf, N. A. Nicola, and N. M. Gough. 1988. Myeloid leukemia inhibitory factor maintains the developmental potential of embryonic stem cells. Nature (London) 336:684-687.

27. Zimmer, A., and P. Gruss. 1989. Production of chimaeric mice containing embryonic stem (ES) cells carrying a homoeobox Hox 1.1 allele mutated by homologous recombination. Nature (London) 338:150-153. 